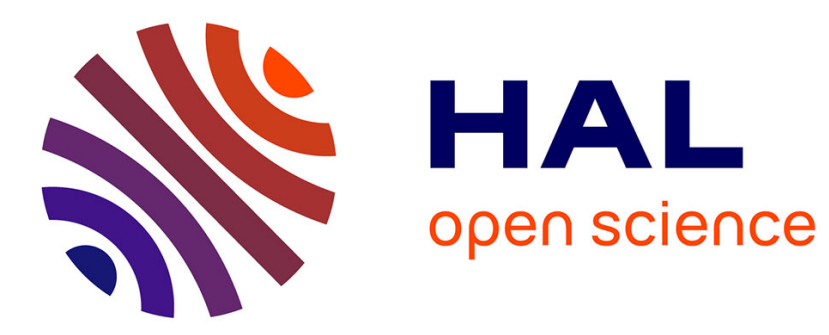

\title{
High Level Petri Nets Based Approach for Analysing Conceptual Objects for Production Systems Simulation
}

\author{
Karim Tamani, Reda Boukezzoula, Georges Habchi
}

\section{To cite this version:}

Karim Tamani, Reda Boukezzoula, Georges Habchi. High Level Petri Nets Based Approach for Analysing Conceptual Objects for Production Systems Simulation. INCOM 2006, May 2006, SaintEtienne, France. Vol. 1, pp. 361-366. hal-00403820

\section{HAL Id: hal-00403820 \\ https://hal.univ-smb.fr/hal-00403820}

Submitted on 28 Sep 2011

HAL is a multi-disciplinary open access archive for the deposit and dissemination of scientific research documents, whether they are published or not. The documents may come from teaching and research institutions in France or abroad, or from public or private research centers.
L'archive ouverte pluridisciplinaire HAL, est destinée au dépôt et à la diffusion de documents scientifiques de niveau recherche, publiés ou non, émanant des établissements d'enseignement et de recherche français ou étrangers, des laboratoires publics ou privés. 


\title{
HIGH LEVEL PETRI NETS BASED APPROACH FOR ANALYSING CONCEPTUAL OBJECTS FOR PRODUCTION SYSTEMS SIMULATION
}

\author{
Karim Tamani, Reda Boukezzoula, Georges Habchi \\ LISTIC - ESIA \\ Domaine universitaire \\ B.P. 806 - 74016 Annecy Cedex \\ \{karim.tamani, boukezzoula,habchi\}@univ-savoie.fr
}

\begin{abstract}
In the field of design and analysis of manufacturing systems, models are sometimes built with the help of analytical methods. However, the verification of these models is often addressed by simulation. To check the performance of a manufacturing system, formal methods of design are needed. In this work, the selected modelling and verification tool is a high level Petri net. Based on properties of the generic concept called the Production Processing System (PPS) and developed for modelling and simulation of production resources, this article deals with analysing the PPS by high-level Petri nets (HLPN) formalisms.
\end{abstract}

Keywords: High level Petri nets, Coloured Petri nets, Production Processing System, Simulation, Performance analysis.

\section{INTRODUCTION}

In the development life cycle of manufacturing systems, the verification of analytical models is often addressed via simulation. The modelling is an important stage in which some performed tests using the model allow us to detect design problems issued from incomplete or ambiguous functioning specifications. In this framework, the iterative application using the model of tests and adjustments leads to a more reliable implementation. Moreover, for existent systems, the analysis of the model and results allow us to detect behavioural problems or/and give performance measures. Often, these tests and analysis are done by simulation of the system model. However, to verify the performance of a system and check the correctness of the model, formal methods of design are needed.

Among the existing modelling formalisms, Petri nets (PN) provide a powerful framework to model and analyse production systems. Indeed, their characteristics, graphical presentation and strong mathematical basis, are widely adopted as description formalism in several sciences and automation communities. However, two classical problems arise when applying analytical methods such as PN, instead of simulation (Delamare et al., 2002). The first one is the complexity of the modelling process itself, especially when the model becomes more and more detailed including different aspects of the system. The second one concerns the size of the models generated by such complex systems. These two kinds of problems can be solved by modelling and specifying the system using high level Petri nets (HLPN) (Jensen and Rozenberg, 1991). HLPN have been introduced as an extension to the original formalism allowing to build a compact model of systems. Among the various HLPNs, Hierarchical Coloured Petri Nets (HCPN), proposed by Jensen (Jensen, 1992) is frequently used in modelling and control of manufacturing systems (Zimmermann, 1994; Zimmermann, 1999; Barros et al., 1997). This method allows token identities (colours) handling symbolic marking and building models in a modular way.

\section{RELATED WORK}

Previous work had adopted this formalism in the field of manufacturing systems. Mohan et al. (2004) used coloured Petri nets for modelling automated flexible manufacturing cells. Based on these models, deadlocks are resolved in real-time control context. 
Perkusich et al. (1999) introduced an approach for modelling and analysis of a distributed supervisor for flexible manufacturing systems using coloured Petri nets. Each cell has its supervisor that is responsible for the actions within this cell. These supervisors are independent and cooperate in order to guarantee the execution of production orders. In this context, Makungu et al. (1999) presented an adaptation of a supervisory control theory and a supervisory synthesis problem to a class of coloured Petri nets. In order to reuse coloured Petri nets models, Silva and Perkusich (2004) described and applied a systematic methodology to the flexible manufacturing systems domain. A model of a system can be developed reusing parts of previous designs, instead of modelling always from the scratch.

This work addresses the analysis of previous developed generic concepts used for modelling and simulation of manufacturing systems with the help of hierarchical timed coloured Petri nets (HTCPN).

This paper is organised as follows. Section 3 presents the conceptual object for design and simulation of production systems, called Production Processing System (PPS), its potentials and limits. Section 4 introduces the HTCPN formalism and the correspondence between the PPS and HTCPN. Section 5 illustrates the complementarities of the two approaches through a simple manufacturing system. Some discussion and analysis about structuring of colour classes and colour functions are made in section 6. Finally, concluding and future work are provided in section 7 .

\section{COMPUTER SIMULATION FOR MANUFACTURING SYSTEMS}

Simulation of manufacturing systems design and analysis is widely used as a decision-making tool. In this section, we present a conceptual object, developed in our laboratory (LISTIC), to model and simulate the resources of a production system.

\subsection{The production processing system.}

The production processing system (PPS) is a generic object having all structural and functional characteristics of a production resource (Bakalem et al., 1995). It presents the following properties:

- It defines atoms, grouping the natural succeeding of the three fundamental operations of a resource (receiving, processing and supplying);

- It synthesises the resource and its behaviour at the same time;

- It is a recursive structure able to develop models at different levels of abstraction and hierarchy.

The first and second properties describe a PPS standard behaviour consisting in the three-function cycle: receiving, processing and supplying (Fig. 1). The third property presents the different states that a PPS could have in a given simulation according to the level of detail needed in the model (Fig. 2), and the hierarchical structure allowing the development of models at five different levels (Fig. 3).

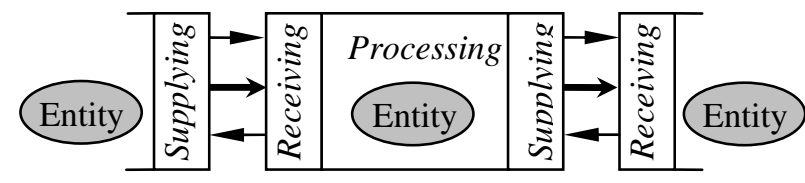

Fig. 1. Sequence of production according to PPS.

\begin{tabular}{|c|c|c|c|c|}
\hline \multirow{11}{*}{ 冚 } & Inactive & & & \\
\hline & \multirow{10}{*}{ Active } & \multirow{4}{*}{ Available } & Idle & \\
\hline & & & \multirow{3}{*}{ Busy } & Intermediate \\
\hline & & & & Saturated \\
\hline & & & & Blocked \\
\hline & & \multirow{6}{*}{ Unavailable } & \multirow{3}{*}{$\begin{array}{l}\text { Planned } \\
\text { stops }\end{array}$} & Break \\
\hline & & & & $\begin{array}{l}\text { Preventive } \\
\text { maintenance }\end{array}$ \\
\hline & & & & $\begin{array}{l}\text { Unplanned } \\
\text { production }\end{array}$ \\
\hline & & & \multirow{3}{*}{$\begin{array}{l}\text { Unplanned } \\
\text { stops }\end{array}$} & Fail \\
\hline & & & & Repair \\
\hline & & & & Set-up \\
\hline & Level1 & Level2 & Level3 & Level4 \\
\hline
\end{tabular}

Fig. 2. Detailed levels and states of PPS.

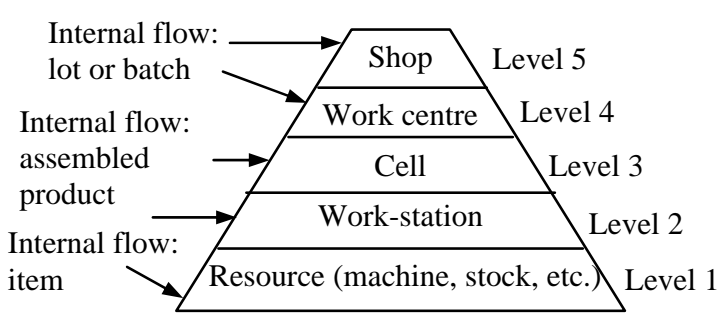

Fig. 3. Hierarchical levels of PPS.

PPS is a recursive object because it is able to model the corresponding resource at each level and is in the same time a function of lower level PPSs.

\subsection{Advantages and limits.}

The main advantages of modelling and simulation using the conceptual object of PPS can be summarized in the following three points:

- The reusability allowed by the generic aspect;

- The possibility of refinement considering the different levels of abstraction;

- The modular modelling property, leading the designer to consider the use of recursive structures of PPS.

In addition, this approach gives an efficient modelling and simulation tool, which offers a simple model building so that a close relationship may exist between the simulation objects and the actual objects. However, the simplicity of the modelling step by PPS is due to no modelling of some structural and behavioural properties, such as absence of deadlocks, boundedness, mutual exclusions, conflicts, etc. Hence, there is no verification step, which allows dynamic properties of a model to be formally proved. To overcome these limits and allow us to verify their properties, we propose to map PPS to a formal model.

To this end, we use the hierarchical timed coloured Petri nets (HTCPN) formalism. This formalism models competition and it provides possibilities to structure and reduce the size of the specifications. 


\section{MODELLING WITH HIGH LEVEL PETRI NETS}

In this paper, the hierarchical timed coloured Petri nets (HTCPN) concept is used. This formalism offer advanced modelling facilities like token colours and hierarchical refinement of transitions. An HTCPN is a set of non-hierarchical nets and each CPN model is then called a CPN page. In the following section, CPN is informally introduced; detailed formal definition may be found in (Jensen, 1992).

Hierarchy is defined by introduction of substitution transitions and fusion places. A substitution transition is a transition which is refined by another CPN page. The page of the substitution transition is called a superpage and the page represented by that transition is called a subpage. The association between subpage and superpage is done by means of sockets and ports. Sockets are all the input and output places of the transition in the superpage. Ports are the places in the subpage associated to the sockets. For simulation and reachability graph generation, sockets and ports are glued together and the resulting model is a flat CPN model. The fusion places are physically different places but logically only one place forming a fusion set. Therefore, all the places belonging to a fusion set have always the same marking. These two additional mechanisms, substitution transition and fusion places, are only graphical, helping building the CPN model. They favour modelling of large and complex systems by giving the designer the possibility to model by abstraction and composition. Fig. 4 illustrates the hierarchical aspect of CPN.

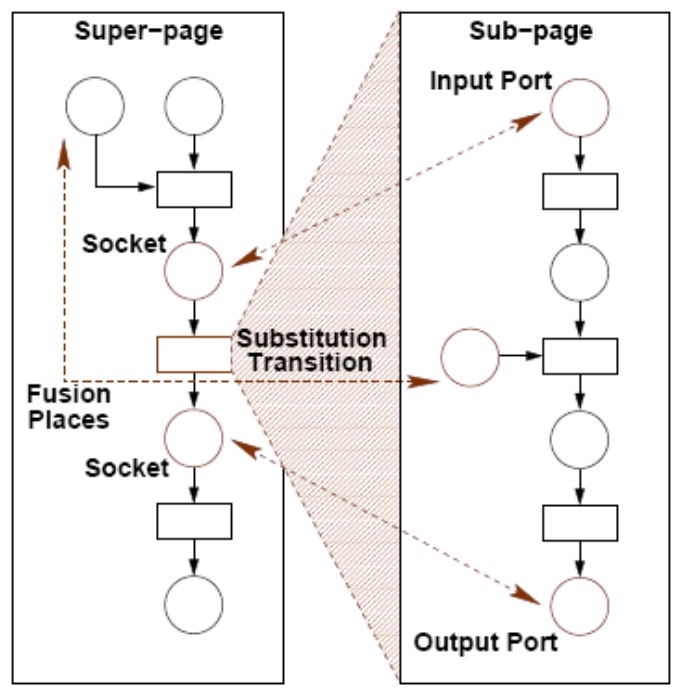

Fig. 4. Hierarchical aspect of CPN.

\subsection{PPS versus HTCPN.}

By considering the main criteria of effectiveness for the PPS concept previously defined and the possibilities of modelling provided by HTCPN, we can make correspondence between PPS and HTCPN as described in Fig. 5, which allows to build the HTCPN associated to a PPS.

\begin{tabular}{|l|l|}
\hline \multicolumn{1}{|c|}{ PPS } & \multicolumn{1}{c|}{ HTCPN } \\
\hline Attributes & Colour sets \\
\hline $\begin{array}{l}\text { Receiving and } \\
\text { supplying }\end{array}$ & Input and output places \\
\hline $\begin{array}{l}\text { Processing } \\
\text { Conditions } \\
\text { Actions }\end{array}$ & $\begin{array}{l}\text { Substitution transition } \\
\text { Input Arcs, guard } \\
\text { Output Arcs (colour } \\
\text { function) }\end{array}$ \\
\hline $\begin{array}{l}\text { Level of hierarchy and } \\
\text { abstraction }\end{array}$ & Notion of page \\
\hline Operating scenarios & Initial marking \\
\hline
\end{tabular}

Fig. 5. PPS versus HTCPN.

\subsection{Building the model with HTCPN.}

Generally, a manufacturing system must respect the following constraints:

- Material constraints characterizing the elements of the process;

- Constraints related to the production routing of each product;

- $\quad$ Processing times.

In this case, the model integrates the material constraints and represents all that it is possible to make in the shop floor independently of the production routings. The structure of the model would reflect the various possibilities of routing of the products within the shop floor. The constraints on the resources would be represented by places initially marked. Colours would be associated to the different products and resources.

The model of the operating scenario indicates the production to be implemented as well as the various operating sequences characterizing each type of product. An operating scenario can be modelled by a sequence of storage a transfer operation and a processing sequence. The trajectory can be specified by the list of the resources " $r$ " needed to process a given product " $p_{i}$ " constituting the processing sequence and the list of handling and transporting materials " $t r_{i}$ " and storage indicating the sequence of transfer.

\section{AN APPLICATION EXAMPLE}

This section deals with a simple manufacturing cell composed of: three machines (M1, M2, M3), one robot (Rob) and two linear accumulating conveyers (CV1, CV2) each one having a capacity of four places as shown in Fig. 6.

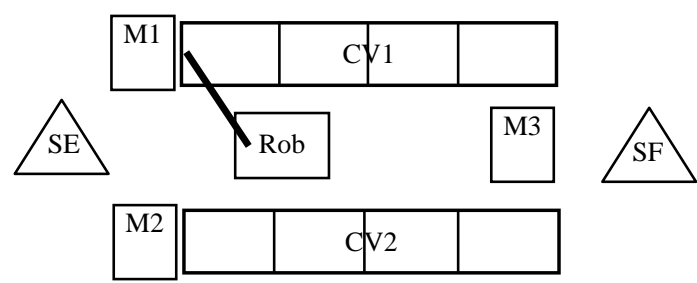

Fig. 6. Layout of the manufacturing cell. 


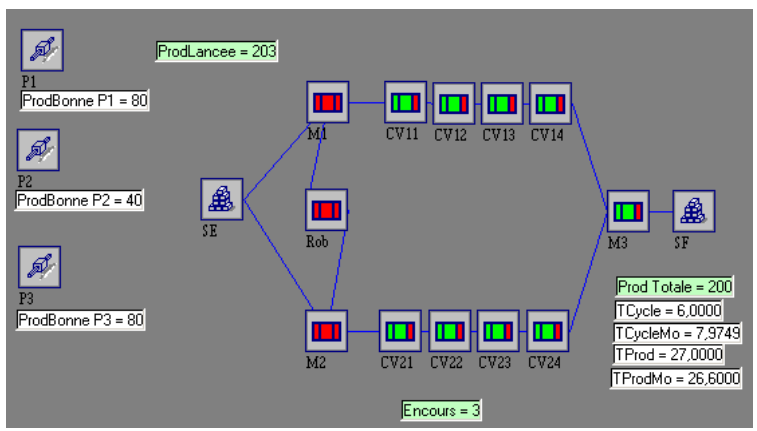

Fig. 7. Knowledge model according to PPS.

The raw materials and finished products enter and leave the system respectively through SE and SF stocks.

\subsection{Modelling and simulation using the PPS concept.}

An analysis according to the PPS concept consists in representing each element of this system (resource) by a PPS block and the product by a Moving Entity (Fig. 7).

In this example, the manufacturing cell processes three different types of products P1, P2 and P3. This is modelled by the Moving Entity concept, which represents the production route defining the path on resources and processing times (see Table 1). The moving entity models the event time that triggers the dynamic of the manufacturing system in the context of discrete event simulation.

$\underline{\text { Table } 1 . \text { Product routings }}$

\begin{tabular}{ccccccccc} 
& SE & M1 & Rob & M2 & CV1 & CV2 & M3 & SF \\
\hline P1 & 0 & 6 & 4 & 8 & --- & 4 & 5 & 0 \\
P2 & 0 & 8 & --- & --- & 4 & --- & 10 & 0 \\
P3 & 0 & --- & --- & 10 & --- & 4 & 6 & 0 \\
\hline
\end{tabular}

The production orders for the three kinds of products are given in Table 2. It provides lot sizes, dates of the first release and order intervals.

Table 2. Production orders

\begin{tabular}{cccc} 
Product & Lot size & Date of the $1^{\text {st }}$ lot & Order interval \\
\hline P1 & 1 & 0 & 20 \\
P2 & 1 & 0 & 40 \\
P3 & 1 & 0 & 20 \\
\hline
\end{tabular}

The manufacturing cell has been modelled and simulated with the Apollo platform (Habchi and Berchet, 2003), in which the described concepts have been implemented. It is a discrete event software simulation tool, which provides a user-friendly graphical interface for modelling and simulation of manufacturing systems (Fig. 7). Depending on the level of abstraction (PPS hierarchical levels and states) different analysis, approximations and simulations can be performed, such as the determination of the failure and repair behaviour of the resources, which can be deterministic or more generally distributed. This results in a adapted approximation of the real behaviour, as demonstrated by an industrial application carried out in the company Alcatel with the help of the Apollo platform (Berchet, 2000).

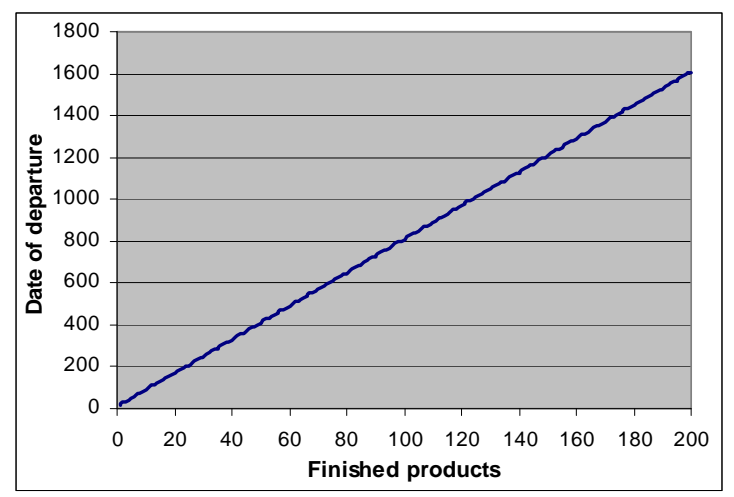

Fig. 8. Dates of departure for finished products.

A series of performance indicators is associated to each component of the manufacturing model. In our example, we consider the departure times of every finished product as the main performance measure. Fig. 8 presents the departure dates of 200 parts as obtained with the help of the Apollo model.

\subsection{Modelling with HTCPN.}

In this section we present the model for the previous application of the manufacturing cell. We apply a hierarchical modelling approach, thus the resulting model is a hierarchical coloured Petri nets. We also use the CPN Tools (Ratzer et al., 2003) in order to draw the graphical model and perform analysis.

Structure of the model. Fig. 9 shows the main page which corresponds to the high level of abstraction of the model. Due to lack of space, the page of declarations is not shown in this paper. It contains the declarations for the colour sets (domains), the variables and the functions. So, only the main page presented in Fig. 9 is detailed.

In this model, places and transitions have the following meaning:

Places SE and SF model the arrival (reps. the departure) of the raw (resp. finished) part stocks of the system. Places EM and SM model the input and output buffers for the machines.

Transitions EC and SC model the raw and finished stocks of the system. TPM models the transport materials (robot and conveyers); $M_{i}$ model the machine i $(\mathrm{i}=1,2,3)$.

In the follow, we adopt the notation given in (Barros et al., 1997). The entry place for the net (place SE) has an initial marking corresponding to the following information: $\quad q_{1}{ }^{\text {( }}$ product $_{1}$, $\quad$ seq_processing ${ }_{1}$, seq_transfert 1$)+\ldots+q_{k}{ }^{`}$ product $_{k}$, seq_processing , $_{\text {, }}$ seq_transfert $t_{k}$, where product $_{k}$ specifies a production order on $q_{k}$ item of product $t_{k}$, and seq_processing ${ }_{k}$, seq_transfert ${ }_{k}$ specifies the 
production route for product $_{k}$. In the presented application, we could have the following initial marking: $1^{`}(p 1,[m 1, m 2, m 3],[r o b, c v 2])$ that means, the system has to produce one item of product P1 with the processing route given in Table 1.

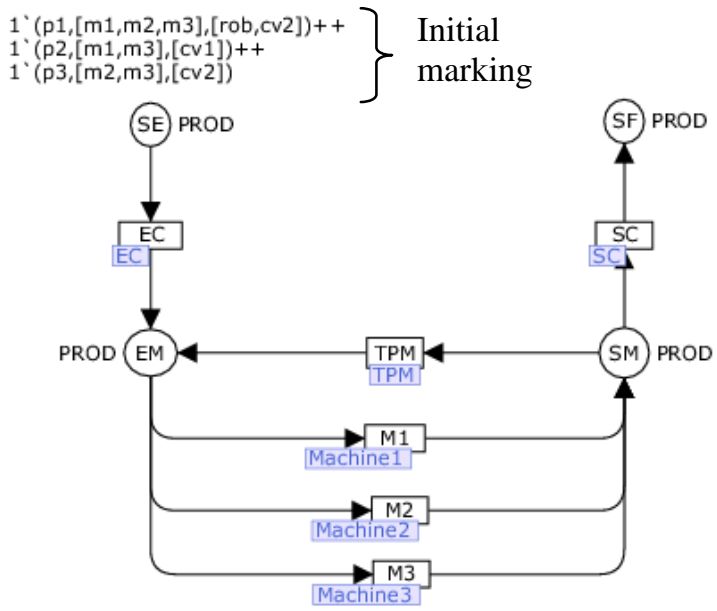

Fig. 9. Main page for the model.

Each time the transition modelling the resource fires, the head of the list of seq_processing ${ }_{k}$ or seq_transfert $_{k}$ is removed, indicating that the resource was already used. The finished product is indicated by token (colour) in place SF with empty lists.

In order to evaluate the temporal behaviour of the HTCPN, we attach timestamp to every token. This timestamp indicates the time a token becomes available. The enabling time of a transition is the maximum timestamp of the tokens to be consumed. The difference between the firing time and the timestamp of a produced token is the firing delay associated to the transition (or to the arc). If at any time, more than one transition is enabled, the transition with the smallest enabling time fires. If several enabled transitions have the same enabling time, one of them fires, leading to a nondeterministic choice.

Model analysis. CPN Tools integrates two modules for the analysis of coloured Petri nets:

- Verification of temporal performance,

- Reachability graph building to verify behavioural properties.

The verification of the model has been performed by evaluating the time consumed of tokens (colours) at the place SF (Fig. 10). The obtained results have been verified by comparing with those corresponding of the PPS model. Fig. 11 illustrates the difference between the temporal performances (departure dates) obtained with PPS and HTCPN models, which remain constant between two bounds. The relative error (\%) compared to the PPS model, shown in Fig. 12 , is due to conflicts that occur in the HTCPN model when more than one token are enabled. Indeed, in the Apollo model, the parts are always released in a predefined order, while the firing order of transition is random in the HTCPN model when the timestamp of more than one token in the same place are identical. This is the case in the place SE, which models the inter arrival time between parts in the system. This causes some backlog in the HTCPN model compared to the PPS model. The analysis of the reachability (or occurrence) graph performed by the CPN Tools shows that all tasks were performed without deadlocks in all possible execution sequences. The practical applicability of the occurrence graph method is however hampered by severe drawback, the well-known state explosion problem. A brief discussion about the reduction of the state space will be done in the next section.

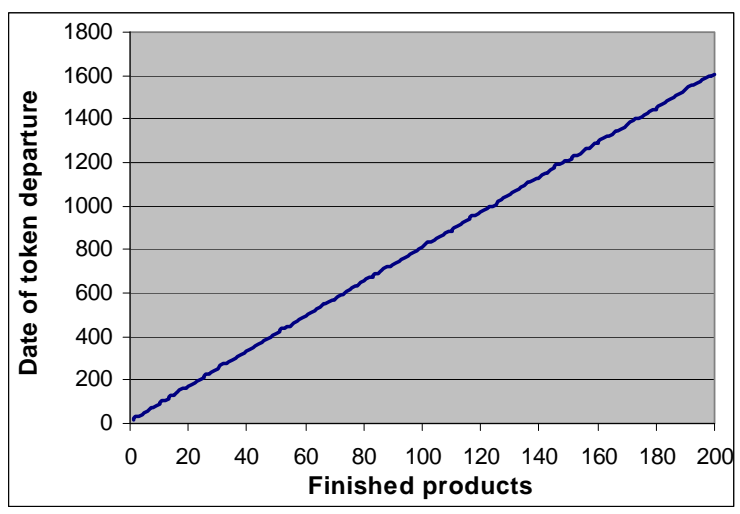

Fig. 10. Dates of token departure at place SF.

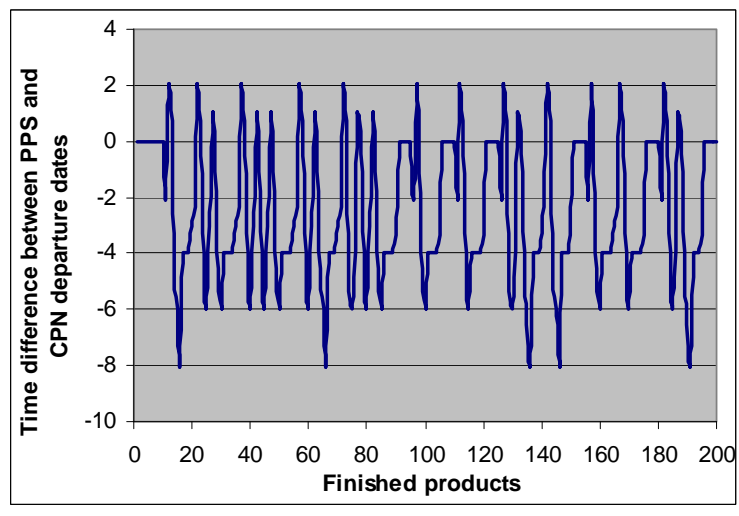

Fig. 11. Difference of temporal performance in both models.

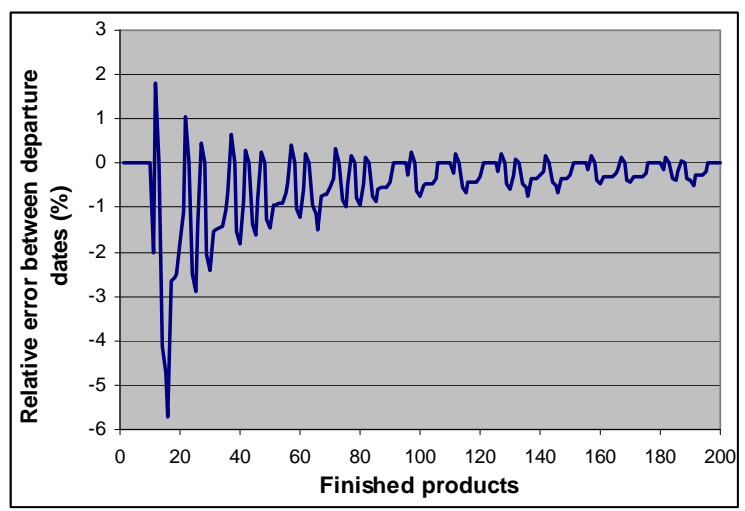

Fig. 12. Relative error between departure dates in both models. 


\section{DISCUSSION}

Managing the inherent complexity of the state space analysis is a major challenge of research. Several clever approaches have been proposed. Most of them are based on the notion of symmetry, which appears when a system is composed of similar components. In the context of the well-formed coloured nets, which have narrow syntactical restrictions on arc expressions, guards, and initial markings, a symbolic reachability graph, in which symmetric markings are automatically lumped into one node, leads to a reduced graph (Chiola et al., 1997). Stochastic Wellformed coloured nets (SWN) is the coloured version of Well Formed nets. The purpose of creating a model in this class is not only to study logical behaviour, but also to study performance issues (Delamare et al., 2002). Also, based on the symmetry of the model, Jensen (1996) developed a technique to construct reduced graph without losing information by means of a permutation of the markings. A number of other methods are described in (Jorgensen, 1997).

\section{CONCLUSION}

In this paper, based on the main criteria of efficiencies of the PPS concept, we showed that highlevel Petri nets can be used for modelling and analysis of production systems. Moreover, high-level Petri nets can be used at many levels of abstraction. We used the hierarchical timed coloured Petri nets in our study. To guide modelling of production systems, we also indicated how to structure complex production systems. This model has been analysed with the help of CPN Tools. The result of the analysis has been successfully compared with performances obtained by simulation with the PPS model using the Apollo platform. This study shows that analysing the PPS concept with high-level Petri nets, we are able to respect the various criteria of effectiveness brought by the PPS concept and to add a verification step to the model.

Future work concerns the development of a control methodology, which integrates intelligent control in the simulation model (Berchet, 2000).

\section{REFERENCES}

Bakalem, M., G. Habchi and A. Courtois (1995). PPS: a contribution for manufacturing systems simulation. Proceedings of the (SCSC'95), Ottawa, Canada.

Barros, T. C., A. Perkusich and J.C.A. Figueiredo (1997). A fault tolerance coloured Petri net resource allocation manager for flexible manufacturing systems. IEEE International conference on Systems, Man, and Cybernetics, p. 1210-1215.

Berchet, C. (2000). Modélisation pour la simulation d'un système d'aide au pilotage industriel. Ph.D. Thesis, University of Grenoble, INP, France.
Chiola, G., C. Dutheillet, G. Franceschinis and S. Haddad (1997). A symbolic reachability graph for coloured Petri nets. Theoretical Computer Science, 176, p. 39-65.

Delamare, C., Y. Gardan and P. Moreaux (2002). Performance evaluation of manufacturing systems with stochastic well formed nets: a case study. In Petri Nets in Design, Modelling and Simulation of Engineering Systems, Pasadena, USA.

Habchi G. and C. Berchet (2003). A model for manufacturing systems simulation with control dimension. Simulation Modelling Practice and Theory, 11, p. 21-44.

Jensen K. and G. Rozenberg (1991). High-level Petri Nets. Theory and Application, Springer-Verlag.

Jensen K. (1992). Coloured Petri Nets. Basic Concepts, Analysis Methods and Practical Use. Volume 1, Basic Concepts. Springer-Verlag.

Jensen K. (1996). Condensed State Space for Symmetrical Coloured Petri Nets. 9, Kluwer Academic Publishers.

Jorgensen J.B. (1997). Analysing Coloured Petri Nets by the Occurrence Graph Method, PhD Thesis, University of Aarhus, Denmark.

Perkusich, A., Z. B. de Sa Rideiro and T. C. Barros. (1999). Modeling and Analysis of a Distributed Supervisor for Manufacturing Systems. In: $5^{\text {th }}$ international conference on CAD/CAM Robotics $\&$ Factories of the future, Brazil.

Makungu, M., R. St-Denis and M. Barbeau (1999). Synthesis of controllers of processes modelled as coloured Petri nets. Discrete Event Dynamic Systems: Theory and Applications, 9, p. 147-169.

Mohan, S., A. Yalcin and S. Khator (2004). Controller design and performance evaluation for deadlock avoidance in automated flexible manufacturing cells. Robotics and ComputerIntegrated Manufacturing, 20, p. 541-551.

Ratzer, A.V., L. Wells, H.M. Lassen, M. Lausen, J.F. Qvortrup, M.S. Stissing, M. Westergaard, S. Christensen and K. Jensen (2003). CPN Tools for Editing, Simulating, and Analysing Coloured Petri Net. LNCS, p. 450-462.

Silva, L. D. and A. Perkusich (2004). A Systematic and Formal Approach to the Specification of Flexible Manufacturing Systems Reusing Coloured Petri Nets Models. In: INCOM 04 11th IFAC Symposium on Information Control Problems in Manufacturing, Bahia, Brazil.

Zimmermann, A. (1994). A Modeling Method for Flexible Manufacturing Systems based on Colored Petri Nets. In: Proc. Int. Workshop on new directions of control and manufacturing, Hong Kong, p. 147-154.

Zimmermann A. and G. Hommel (1999). Modelling and Evaluation of Manufacturing Systems Using Dedicated Petri Nets. Int. Journal of Advanced Manufacturing Technology, 15, p. 132-137. 